\title{
Diabetes Diagnostic Markers in Periodontitis Patients
}

\author{
Somaye Ansari Moghadam,,$^{, *}$ and Sara Abasi ${ }^{2}$ \\ ${ }^{1}$ Periodontology Department, Oral and Dental Disease Research Center, Zahedan University of Medical Sciences, Zahedan, IR Iran \\ ${ }^{2}$ Zahedan University of Medical Sciences, Zahedan, IR Iran \\ "Corresponding author: Somaye Ansari Moghadam, Periodontology Department, Oral and Dental Disease Research Center, Zahedan University of Medical Sciences, Zahedan, \\ IR Iran. E-mail: s_a_moghadam@yahoo.com
}

Received 2015 October 01; Revised 2015 October 15; Accepted 2015 November 15.

\section{Dear Editor,}

Although the diagnostic role of the A1C is clear in patients with diabetes, as shown by evidence that even a reduction of $1 \%$ in the A1C level may also cause a reduction of $21 \%$ of death due to diabetes, $14 \%$ in myocardial defects and $37 \%$ in micro vascular complications (1), it appears that A1C cannot be a reliable diagnostic marker for the diagnosis of diabetes risk in diabetes-free patients with chronic periodontitis. Hayashida et al. (2) and Rajan et al. (3) observed a significant relationship between A1C levels and chronic periodontitis, in which the A1C levels in people with periodontal disease was reported to be higher than healthy controls; this trend was reversed in another study that showed higher A1C levels in healthy controls than chronic periodontitis patients (4). This finding is consistent with the study of Pajunen et al. (5), which demonstrated that the sensitivity of $\mathrm{A1C} \geq 6.5 \%$ for the diagnosis of diabetes is $39 \%$, while $61 \%$ of individuals with diabetes had $\mathrm{A1C}<$ $6.5 \%$, and the measurement of A1C level had delayed the diagnosis of diabetes in $61 \%$ of the patients. Furthermore, Anand et al. (6) did not consider A1C as a reliable test for the diagnosis of diabetes since it is influenced by conditions such as malaria, anemia, ethnicity and infection. According to reports by the American association for clinical chemistry (7), when people are categorized based on their A1C level in groups of $<5 \%, 5 \%-5.5 \%$ and $>5.5 \%$, the risk of cardio-vascular events, heart disease and stroke were minimum in the group with A1C levels between 5 and 5.5\%, while it was maximum in the group with an A1C level higher than 5.5\%. In the study of Ansari Moghadam (4), although the A1C level in healthy controls was higher than patients with chronic periodontitis, it ranged between 5 and 5.5\% in healthy individuals and below $5 \%$ in chronic periodontitis patients. This implies that an A1C level below 5\% might expose people to higher rate of mortality than those with A1C levels between 5 and 5.5\%. However, the main question is which diagnostic test can be used as a gold standard predictor of diabetes in non-diabetic individuals? Unfortunately, a precise gold standard for comparing the diagnostic tests of diabetes is not available and, to date remains controversial (8). Carson et al. manifested that changes in laboratory parameters had little effect on the prevalence of diabetes and the utilization of $\mathrm{A} 1 \mathrm{C}$ instead of fasting plasma glucose (FPG) did not show a noteworthy change in the prevalence of diabetes and these two tests were similar in $97.7 \%$ of cases (9). However, epidemiological studies by Cowie et al. showed that the measurements with glucose plasma and $\mathrm{A} 1 \mathrm{C}$ was different in various populations, as $\mathrm{A1C}$ could recognize $30 \%-40 \%$ of diabetics whose disease was not detected, Whereas this rate was 50\% for FPG, and $90 \%$ for two-hour plasma glucose (2-h PG) (10). Similar results were found by the IRAS study (11).

In major pathophysiologic abnormalities, $\mathrm{A} 1 \mathrm{C}$ is a poor marker, while tests like FPG and two-hour PG run much better than any other diagnostic assay. If the diagnosis of diabetes is based only on A1C, a large proportion of patients with diabetes would be missed while detection of such patients is only possible with oral glucose tolerance test (OGT) (8).

Since periodontal infections caused by gram negative bacteria (G-), result in an insulin resistance increase, consequently deteriorated glycemic control, (increased insulin resistance may occur in both diabetic or non-diabetic individuals) (12) and the use of a OGT to assess the association between periodontal disease and diabetes risk may be more beneficial. To determine an appropriate gold standard for assessing the risk of diabetes in diabetic and nondiabetic individuals more studies should be conducted.

\section{References}

1. Stratton IM, Adler AI, Neil HA, Matthews DR, Manley SE, Cull CA, et al. Association of glycaemia with macrovascular and microvascular complications of type 2 diabetes (UKPDS 35): prospective observational study. BMJ. 2000;321(7258):405-12. [PubMed: 10938048].

2. Hayashida H, Kawasaki K, Yoshimura A, Kitamura M, Furugen R, Nakazato $\mathrm{M}$, et al. Relationship between periodontal status and HbA1c in nondiabetics. J Public Health Dent. 2009;69(3):204-6. doi: 10.1111/j.1752-7325.2009.00122.x. [PubMed: 19486462].

3. Rajan P, Nera M, Pavalura AK, Medandrao N, Kumar SC. Comparison of glycosylated hemoglobin (HbA1C) levels in patients with chronic periodontitis and healthy controls. Dent Res J (Isfahan). 2013;10(3):38993. [PubMed: 24019810]. 
4. Ansari Moghadam S, Abbasi S, Sanei Moghaddam E, AnsariMoghaddam A. Is HbA1c an Accurate Predictor for Diabetes Risk in Patients with Chronic Periodontitis?. Iran J Public Health. 2014;43(8):1165. [PubMed: 25927054].

5. Pajunen P, Peltonen M, Eriksson JG, Ilanne-Parikka P, Aunola S, Keinanen-Kiukaanniemi S, et al. $\mathrm{HbA}(1 \mathrm{c})$ in diagnosing and predicting Type 2 diabetes in impaired glucose tolerance: the Finnish Diabetes Prevention Study. Diabet Med. 2011;28(1):36-42. doi:10.1111/j.14645491.2010.03183.x. [PubMed: 21166843].

6. Anand SS, Razak F, Vuksan V, Gerstein HC, Malmberg K, Yi Q, et al. Diagnostic strategies to detect glucose intolerance in a multiethnic population. Diabetes Care. 2003;26(2):290-6. [PubMed:12547851].

7. Defining HbA1C's role in non-diabetics,Will this measurementbecome a risk assessment tool for all adults? Genna Rollins. Available from: http://www.aacc.org/publications/strategies/archives/ documents/051310CLS.2011.

8. Bonora E, Tuomilehto J. The pros and cons of diagnosing diabetes with A1C. Diabetes Care. 2011;34 Suppl 2:S184-90. doi:10.2337/dc11-s216. [PubMed: 21525453].
9. Carson AP, Reynolds K, Fonseca VA, Muntner P. Comparison of A1C and fasting glucose criteria to diagnose diabetes among U.S adults.Diabetes Care. 2010;33(1):95-7. doi:10.2337/dc09-1227. [PubMed 19808920].

10. Cowie CC, Rust KF, Byrd-Holt DD, Gregg EW, Ford ES, Geiss LS, et al. Prevalence of diabetes and high risk for diabetes using A1C criteria in the U.S. population in 1988-2006. Diabetes Care. 2010;33(3):562-8. doi: 10.2337/dc09-1524. [PubMed: 20067953].

11. Lorenzo C, Wagenknecht LE, Hanley AJ, Rewers MJ, Karter AJ, Haffner SM. A1C between 5.7 and $6.4 \%$ as a marker for identifying pre-diabetes, insulin sensitivity and secretion, and cardiovascular risk factors: the Insulin Resistance Atherosclerosis Study (IRAS). Diabetes Care. 2010;33(9):2104-9. doi: 10.2337/dc10-0679. [PubMed: 20573754].

12. Ryu H, Tran H, Ware MW, Iker B, Griffin S, Egorov A, et al. Application of leftover sample material from waterborne protozoa monitoring for the molecular detection of Bacteroidales and fecal source tracking markers. J Microbiol Methods. 2011;86(3):337-43. doi: 10.1016/j.mimet.2011.06.001. [PubMed: 21693138]. 